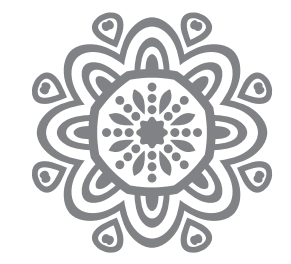

\title{
Kecerdasan Networking Dalam Dakwah Islam
}

\author{
Akhmad Shunhaji \\ Dosen Pascasarjana Institut PTIQ Jakarta \\ shunhaji.akhmad@yahoo.com \\ Hр. 085215243740
}

\begin{abstract}
Abstrak: Kecerdasan networking merupakan kecerdasan dasar yang dikembangkan dari potensi sosial manusia. Sejak lahir, manusia telah memiliki kecerdasan networking sebagai dasar pengembangan sifat sosial kemanusiaannya. Kecerdasan ini dapat dimanfaatkan untuk pelaksanaan dakwah Islam. Kecerdasan networking memberikan kontribusi positif kepada para Dai dalam melaksanakan dakwah. Para dai yang melaksanakan dakwah dengan menjalankan prinsip-prinsip kecerdasan networking, cenderung diterima dengan baik oleh masyarakat.
\end{abstract}

Kata Kunci: kecerdasan, networking, dakwah

\section{A. Pendahuluan}

Penduduk Indonesia secara kuantitas terus mengalami peningkatan. Peningkatan kuantitas juga terdapat pada jumlah penduduk yang mengaku Muslim. Menurut Badan Pusat Statistik tahun 2010, penduduk Muslim Indonesia tahun 1971 sebanyak 103.58 juta jiwa (87,51\%), 1980 sebanyak 128, 46 juta jiwa (87, 94\%), 1985 sebanyak 142, 59 juta jiwa (86, 92\%), 1990 sebanyak 156, 32 juta jiwa (87, 21\%), 2000 sebanyak 177, 53 juta jiwa (88, 22\%), 2005 sebanyak 189, 01 juta jiwa (88, 58\%), dan 2010 sebanyak 207, 18 juta jiwa $(87,18 \%)^{1}$.

Menteri Dalam Negeri menyebutkan bahwa jumlah penduduk Indonesia hingga Maret 2017 sebanyak 257.912.349 jiwa² $^{2}$. Jika dari jumlah tersebut dihitung menggunakan prosentase penduduk Muslim yang sama besar dengan

${ }^{1}$ https://sp2010.bps.go.id/index.php/site/tabel?tid=321 diakses pada 25 Oktober 2017.

${ }^{2}$ http://www.kemendagri.go.id/news/2017/04/15/ diakses pada 25 Oktober 2017. 
tahun 2010, maka penduduk Muslim Indonesia mencapai 225 juta jiwa. Dari seluruh umat Muslim tersebut, kemampuan agamanya sangat beragam. Mereka berpotensi sebagai obyek dakwah para Dai.

Secara umum, kemampuan beragama umat Muslim dapat dibagi menjadi empat. Pertama, mereka memahami pengetahuan agama dan mengamalkan pengetahuannya dalam kehidupan berbangsa dan bernegara. Kedua, mereka memahami pengetahuan agama, tetapi tidak mengamalkan pengetahuan yang dimiliki dalam kehidupan berbangsa dan bernegara. Ketiga, mereka tidak memahami pengetahuan agama tetapi merasa paham dengan ajaran agama. Kelompok ketiga ini mengamalkan pengetahuan semunya dalam kehidupan berbangsa dan bernegara. Keempat, mereka yang tidak memahami pengetahuan agama dan tidak bisa mengamalkan ajaran agama dalam kehidupan berbangsa dan bernegara.

Keempat model beragama tersebut, menjadi wilayah dakwah para Dai melaksanakan tugasnya. Karakteristik mereka mungkin beragam. Kebutuhan mereka terhadap dakwah agama juga beragam. Walaupun karakteristik dan kebutuhan mereka berbeda, pengembangan kecerdasan networking para Dai dimungkinkan menjadi solusi alternative yang tepat. Tulisan ini memaparkan kecerdasan networking dalam dakwah Islam.

\section{B. Networking sebagai Kecerdasan Dai}

\section{Pengertian}

Kecerdasan networking adalah kemampuan individu memanfatkan potensi sosialnya untuk menjalin relasi yang saling menguntungkan dalam jangka panjang dengan orang lain. Kecerdasan networking merupakan pengembangan potensi sosial individu yang dibawanya sejak lahir. Pengembangan potensi ini diarahkan pada arah yang memberikan manfaat pada diri dan orang lain dalam jangka panjang.

Seperti yang telah lazim diketahui bahwa manusia dilahirkan di dunia dengan membawa potensi sosial. Bayi yang terlahir dengan kedua kaki sempurna, belum dapat berjalan, ataupun berlari. Kedua kaki tersebut, nantinya dapat dimanfaatkan berjalan menuju tempat kerja yang menghasilkan upah/gaji, atau bermain bola yang menghasilkan miliaran uang. Namun, semuanya masih dalam bentuk potensi yang memerlukan pengembangaan agar berfungsi sesuai yang seharusnya dalam konteks berhubungan dengan orang lain.

Al-Qurân memberikan informasi adanya potensi sosial yang dibawa oleh manusia tersebut. Al-dilâlah dalam beberapa ayat al-Qurân mengarah pada 
kompetensi sosial ini. Di antara ayat yang memiliki al-dilâlah pada potensi sosial ini adalah Surat Al-Nahl [16] 78. Allah swt berfirman,

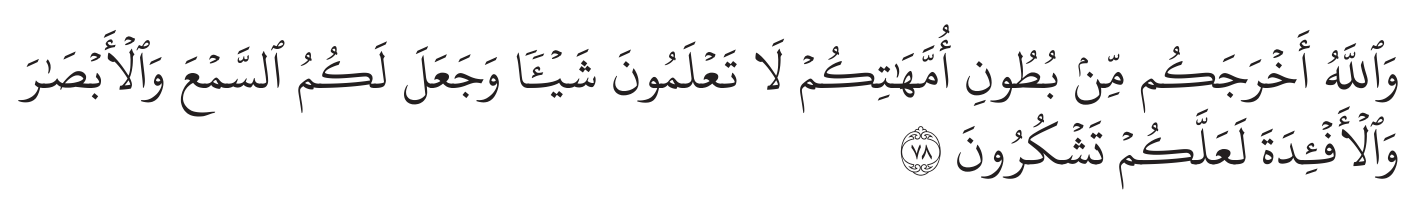

Allah telah mengeluarkan kamu dari perut ibumu dalam keadaan tidak mengetahui sesuatupun. Dan Dia memberi kamu pendengaran, penglihatan, dan hati supaya kamu bersyukur. (QS al-Nahl [16] 78)

Dalam ayat tersebut digambarkan bahwa manusia pada awal kehidupannya belum memiliki kemampuan apa-apa. Allah swt memberinya pendengaran, penglihatan, dan hati (penalaran) yang memiliki potensi besar untuk dikembangkan. Menurut Samarqandy ${ }^{3}$, lâ ta'lamûna ditafsirkan sebagai lâ ta'qiluna, belum memiliki kemampuan menggunakan akal pikirannya secara maksimal. Manusia diberikan pendengaran, penglihatan, dan hati supaya dapat digunakan untuk mengetahui dan membedakan mana yang baik dan buruk. Sementara menurut Imam As-Shawy ${ }^{4}$, kalimat lâ ta'lamûna ditafsirkan sebagai lâ tu'rifûna. Ta'lamûna bermula dari kalimat dasar 'alima-ya'lamu-'ilman yang berarti mengetahui sesuatu sedangkan tu'rifûna berasal dari kalimat dasar 'arafa-yu'rifu-'irfatan - 'irfânan nan yang berarti mengetahui atau mengenal sesuatu ${ }^{5}$. Keduanya memiliki terjemahan yang serupa namun memiliki perbedaan.

Dalam KBBI, ilmu adalah kepandaian terutama dalam hal Islam atau kesalehan, sedangkan arif didefinisikan sebagai bijaksana, cerdik, dan pandai ${ }^{6}$. Baik ditafsirkan ta'lamûna maupun tu'rifûna keduanya bukan muncul secara instan. Keduanya masih berbentuk potensi yang masih memerlukan pengembangan.

Pengembangan yang dimaksudkan pada ayat di atas adalah pengembangan potensi pendengaran, penglihatan, dan hati. Ketiga potensi tersebut merupakan potensi sosial manusia, bukan sekedar potensi individual. Dengan ketiganya, manusia akan melakukan interaksi dengan yang lain.

Pengembangan potensi sosial ini, dimungkinkan memiliki hubungan erat dengan pengembangan kepribadian manusia. Kepribadian dimaksudkan

\footnotetext{
${ }^{3}$ Abu Al-laits Nashr ibn Muhammad ibn Ahmad ibn Ibrahim Al Samarqandy, Bahrun Al 'Ulum, Beirut: Dâr Al-Kutub Al-'Alamiyah, t.th, h. 244

${ }^{4}$ Ahmad bin Muhammad As-Shawy Al Maliky, hâsyiah al-Allâmah al-Shawy 'ala Tafsir al-Jalâlain, Jilid 2, Beirut: Dar al Fikr, t.th, h. 321.

${ }^{5}$ Ahmad Sya'bi, Kamus Annur: Indonesia-Arab, Arab Indonesia, Surabaya: Penerbit Halim, 1997, h. 157-166

${ }^{6}$ http://kbbi.web.id/alim, diakses pada 27 September 2017.
} 
sebagai organisasi dinamis dari sistem psiko-fisik dalam individu yang turut menentukan cara-cara yang khas dalam menyesuaikan dirinya dengan lingkungan ${ }^{7}$. Pribadi manusia bukan sekedar kesatuan organ-organ tubuh atau suatu individu yang berdiri sendiri saja. Individu sebagai individu yang utuh tersebut harus dibarengi dengan kemampuan melakukan hubungan dengan orang lain. Kepribadian individu ini dapat disebut sebagai kepribadian apabila terjadi kesatuan utuh pada keseluruhan sistem psiko-fisik, bakat, kecakapan dan ciri-ciri kegiatannya. Kesatuan dari berbagai entitas yang membangun kepribadian tersebut, akan selalu berhubungan dengan lingkungan yang ada di luar dirinya. Dengan demikian, pengembangan potensi sosial memberikan sumbangan yang sangat berarti terhadap kepribadiannya.

Secara umum, hubungan individu dengan lingkungan dapat dibagi menjadi empat jenis. Individu dapat bertentangan dengan lingkungan, individu dapat memanfaatkan lingkungan, individu dapat menyesuaikan lingkungan, dan individu dapat berpartisipasi pada lingkungannya. Individu mungkin melakukan jenis hubungan yang berbeda-beda. Namun demikian, hubungan utama yang nampaknya diinginkan oleh kebanyakan manusia adalah individu yang senantiasa berusaha menyesuaikan diri dengan lingkungannya. Dalam kontek ini, mereka yang mampu mengembangkan kecerdasan networking dengan baik memiliki potensi besar dapat menyesuaikan dan diterima oleh lingkungannya.

Hal ini sesua dengan perintah Allah swt dalam QS. al-Hujurat [49] 13,

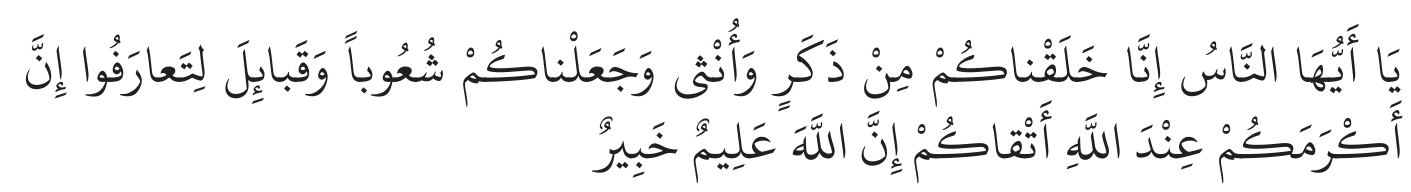

"Hai manusia, sesungguhnya Kami menciptakan kamu dari seorang laki-laki dan seorang perempuan dan menjadikan kamu berbangsa-bangsa dan bersuku-suku supaya kamu saling mengenal. Sesungguhnya orang yang paling mulia di antara kamu di sisi Allah ialah orang yang paling bertakwa di antara kamu. Sesungguhnya Allah Maha Mengetahui lagi Maha Mengenal'. (QS al-Hujurat [49] 13).

Kalimat litâarafû dalam konteks ayat ini, ditempatkan sebagai respon dari penciptaaan an-nâs dalam jenis laki-laki dan perempuan. Kalimat ini juga menjadi respon adanya an-nâs sebagai bagian dari kelompok, yang digambarkan dengan kalimat syu'ûb dan qabâil. Keberadaan an-nâs sebagai bagian dari jenis maupun kelompok, memberikan pemahaman bahwa manusia sebagai individu

${ }^{7}$ Ngalim Purwanto, Ilmu Pendidikan: Teoritis dan Praktis, Bandung: Remdja Karya, 1985, 
adalah bagian dari jenis manusia atau kelompok manusia. Manusia tidak hidup seorang diri. Dia hidup dengan orang lain dalam kelompknya maupun kelompok orang lain. Dia hidup dalam komunitas dengan jenis sama maupun jenis yang berbeda.

Keberadaan individu bersama orang lain tersebut kemudian diperintahkan untuk litầrafû. Penafsiran terhadap kalimat litâ̂rafû dalam hâsyiah alshâwy memiliki kemiripan dengan kitab Mirâh labîd. Keduanya menekankan pada liya'rifa ba'dlukum ba'dla', supaya keduanya saling mengenal dan memahami. Pemahaman ayat dengan penafsiran di atas diikuti oleh Jamilah Karim. Dalam bukunya American Muslim Women: Negotiating Race, Class, and Gender within the Ummah, Karim menyebutkan,

The verse acknowledges human difference based on collective identity, for example, ethnicity, nationality, and language. The ethical implication of this difference, however, is that human groups are expected to learn about one another, as opposed to remaining ignorant about one another. The Arabic verb ta'arafu comes from the root 'arafa, which means "to know, to come to know. a variation on the root, ta'arafu means they become mutually acquainted, or they came to know one another, referring to a mutual process among groups. through is root 'arafa, ta'arafu is linked to the word ma'ruf. ma'ruf has multiple meanings one of which is good fellowship with one's family and with others of humanity9

Dengan demikian, perintah lita'ârafû dalam ayat di atas dipahami bukan sekedar mengenal nama. Pengakuan terhadap perbedaan berdasarkan identitas kolektif dan saling memahami dalam perbedaan. Seseorang diperintahkan untuk mengenal hingga memahami karakter. Dengan saling mengenal yang demikian, dimungkinkan dapat saling memahami, saling menyayangi, saling mendoakan, dan saling membantu. Perintah litaârafû menyiratkan kebutuhan membangun network dan diperlukannya mengembangkan kecerdasan networking. Demikianlah, bahwa kecerdasan networking merupakan kecerdasan dasar manusia.

Lalu, dimanakah letak kecerdasan networking? Seperti yang telah dipaparkan di atas bahwa setiap individu memiliki potensi sosial. Dalam potensi sosial, manusia membutuhkan manusia yang lain. Bahkan, seandainya manusia yang saling membutuhkan tersebut telah membuat suatu kelompok juga akan membutuhkan kelompok lain. Kebutuhan ini kemudian melahirkan aktivitas yang disebut interaksi sosial.

\footnotetext{
${ }^{8}$ Ahmad Ibn Muhammad Al-Shawy al-Maliky, Hâsyiah al-'allamah al-Shâwy. ... h 114.

${ }^{9}$ Jamillah Karim, American Muslim Women: Negotiating Race, Class, and Gender Within the Ummah, New York: New York University Press, 2009, h. 273.
} 
Interaksi sosial dalam bentuk relasi sosial memungkinkan orang-orang saling berkomunikasi dan berinteraksi. Relasi sosial memiliki pengertian adanya hubungan timbal balik dalam proses pelayanan antara pekerja sosial dengan klien ${ }^{10}$. Namun, hubungan timbal balik di sini memungkinkan adanya pihak yang dianggap lebih tinggi dibanding yang lain. Menurut Foucault, relasi sosial pasti merupakan relasi kuasa, jika relasi sosial itu berbentuk '(ber) kuasa atas' (power over $)^{11}$. Bahkan, dalam pandangan ahli psikologi kritis, relasi sosial memungkinkan adanya dominasi dan penindasan ${ }^{12}$.

Hubungan antar sesama yang digambarkan dalam kecerdasan emosi dan kecerdasan interpersonal juga mungkinkan dalam bentuk relasi (relationship). Relationship diartikan sebagai persahabatan, hubungan, dan pertalian ${ }^{13}$. Relationship juga memiliki bentuk superior dan inverior jika dihubungkan dengan pelanggan. Menurut Frans M Royan, istilah customer relationship management memiliki arti bahwa customer harus dipandang sebagai asset besar yang dimiliki distributor ${ }^{14}$. Pandangan sebagai asset memiliki makna inverioritas customer.

Pandangan di atas memperjelas letak kecerdasan networking. Kemampuan individu untuk membangun relasi dapat terwujud pada dua hal. Pertama, hubungan antar individu atau kelompok dalam bentuk (ber) kuasa atas (power over). Kedua, hubungan dalam bentuk relasi sosial yang saling menguntungkan dalam jangka waktu yang lama (kecerdasan networking).

\section{Prinsip Kecerdasan Networking untuk Dakwah Islam}

Seorang dai memiliki tugas untuk mengajak orang lain agar mau dan mampu mengikuti ajaran-ajaran Islam. Tugas dai seperti ini merupakan manifestasi dari firman Allah swt yang menjelaskan bahwa rusul ditugaskan untuk menyampaikan kabar gembira dan peringatan. Keterangan tersebut terdapat dalam beberapa ayat al-Qurân. Di antara ayat yang menyebutkan penjelasan ini adalah QS. Al- Nisâ’[4] 165.

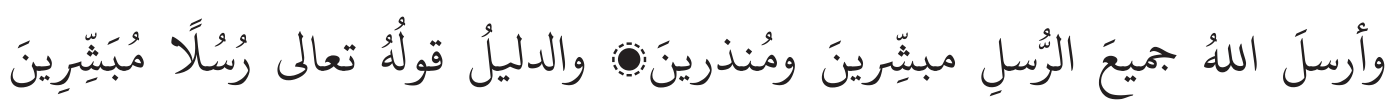

\footnotetext{
${ }^{10} \mathrm{https} / / /$ www.kamusbesar.com/relasi-sosial diakses pada 27 Juli 2017.

${ }^{11}$ Simon Philpott, Meruntuhkan Indonesia Politik Postkolonial \& Otoritarianisme, Yogyakarta: LKiS, 2000, h. 228.

${ }^{12}$ Isaac Prilleltensky \& Dennis Fox, Psikologi Kritis: Metaanalisis Psikologi Modern, Jakarta: Teraju, 2005, h 111.

${ }^{13} \mathrm{http}: / /$ www.kamuskbbi.id/inggris/indonesia.php? $\mathrm{mod}=$ view\&relationship\&id=270 81 -kamus-inggris-indonesia.html.

${ }^{14}$ Frans M Royan, The Smart Marketer in Café: Strategi memaksimalkan Penetrasi Produk, Jakarta: Gramedia Pustaka Utama, 2004, h.83.
} 


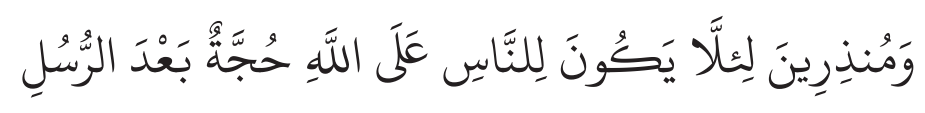

(Mereka Kami utus) selaku rasul-rasul pembawa berita gembira dan pemberi peringatan supaya tidak ada alasan bagi manusia membantah Allah sesudah diutusnya rasul-rasul itu. Dan adalah Allah Mahaperkasa lagi Mahabijaksana. (QS al-Nisa [4] 165).

Sebagai pembawa risalah Rasul, para dai dapat meneladani rasul dalam melaksanakan dakwah. Peneladanan terhadap pelaksanaan dakwah rasul, tentu terbatas dengan kemampuan masing-masing dai. Sekalipun demikian, ditemukan beberapa ajaran rasul yang dapat dijadikan prinsip dasar dalam berdakwah. Di antara prinsip dakwah dalam Islam yang mendasarkan pada kecerdasan networking adalah hubungan bermakna, persamaan frekuensi, dan solusi bermakna.

Seorang Dai hendaknya mampu menduplikasikan dirinya sebagai masyarakat obyek dakwah, kemudian membawa mereka menjadi seperti dirinya. Seorang Dai mungkin dapat diterima oleh masyarakat, jika tidak dianggap bertentangan dengan masyarakat tersebut. Hal demikian, sejalan dengan QS. Al-Taubah [9]128.

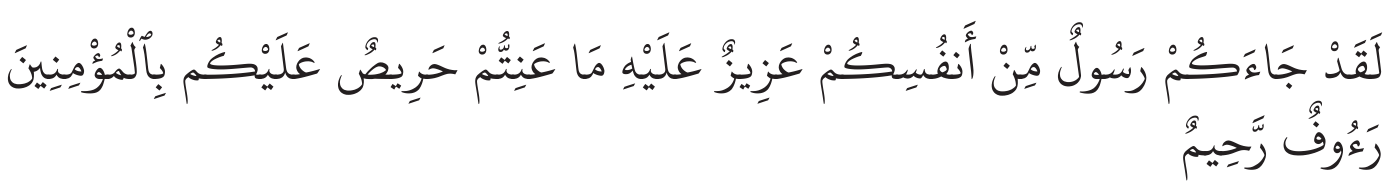

Sungguh telah datang kepadamu seorang Rasul dari kaummu sendiri, berat terasa olehnya penderitaanmu, sangat menginginkan (keimanan dan keselamatan) bagimu, amat belas kasihan lagi penyayang terhadap orangorang mukmin. (QS. Al-Taubah [9]128).

Ayat ini memberikan petunjuk bahwa utusan yang diperintahkan menyampaikan kalam Tuhan kepada manusia adalah dari jenis manusia. Di antara mereka adalah sejenis. Artinya, ketika utusan tersebut memberikan contoh penerapan kalam Tuhan, secara rasional dapat dipahami oleh manusia lain. Ketika utusan Tuhan melaksanakan perintah Tuhan, sangat mungkin perintah tersebut dapat dilaksanakan oleh manusia yang lain. Dia diutus agar diterima kehadirannya, mampu menjalin hubungan bermakna, berada dalam frekuensi yang sama serta mampu memberikan solusi yang berarti.

Konteks pemahaman terhadap ayat di atas juga dapat memberikan petunjuk untuk berkomunikasi dengan bahasa yang dipahami oleh jenis manusia. Bahkan, dalam sebuah hadis marfu', Ali ra mengingatkan agar para sahabat 
mampu menyampaikan dakwah sesuai kemampuan obyek bicaranya sehingga mereka memahaminya dengan baik.

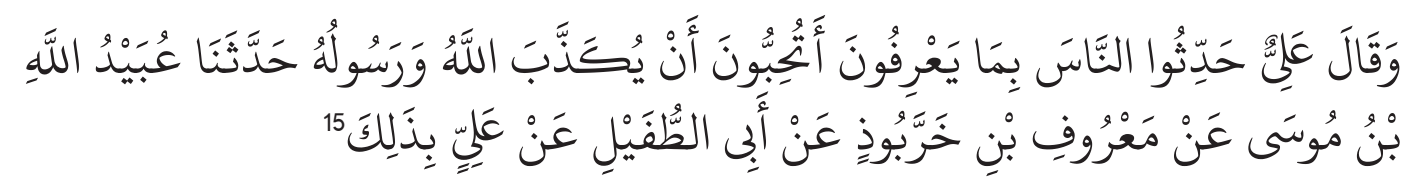

Dan Ali berkata, "Berbicaralah dengan manusia sesuai dengan kadar pemahaman mereka, apakah kalian ingin jika Allah dan rasul-Nya didustakan?” Telah menceritakan kepada kami 'Ubaidullah bin Musa dari Ma 'ruf bin Kharrabudz dari Abu Ath Thufail dari Ali seperti itu.'

\section{Kesimpulan}

Paparan di atas memberikan pemahaman bahwa kecerdasan networking adalah kemampuan individu mengembangkan potensi dasar sosialnya untuk menjalin relasi dengan orang lain. Relasi yang dibangun melalui kecerdasan ini adalah relasi yang saling menguntungkan dalam jangka waktu yang lama. Pemahaman ini, mengecualikan pada kemampuan membangun relasi positif jangka pendek dan relasi negatif.

Kecerdasan networking memberikan kontribusi positif kepada Dai dalam menjalankan aktivitas dakwahnya. Para Dai memiliki tanggung jawab syara' untuk menyampaikan dakwah rasul. Penyampaian dakwah dengan memanfaatkan pengembangan kecerdasan networking lebih mungkin diterima oleh masyarakat.

\section{Daftar Pustaka}

Al-Asqalany, Ahmad Ibn Hajar, Fathul Bari Syarah Shohih Al Bukhori, Juz I, Riyadh, Saudi Arabia: Dar Thaibah Riyadh Saudi Arabia, 2005/1426.

Karim, Jamillah, American Muslim Women: Negotiating Race, Class, and Gender Within the Ummah, New York: New York University Press, 2009.

Al-Maliky, Ahmad bin Muhammad Al-Shawy, Hâsyiah al-'allamah al-Shâwy 'ala Tafsir al-Jalâlain. Jilid 4, Beirut: Dar al-Fikr, t.th.

Munawwir, Ahmad Warson, Kamus Al-Munawwir, Surabaya: Pustaka Progressif, 1997.

Philpott, Simon, Meruntuhkan Indonesia Politik Postkolonial \& Otoritarianisme, Yogyakarta: LKiS, 2000.

${ }^{15}$ Ahmad Ibn Hajar Al-Asqalany, Fathul Bari Syarah Shohih Al Bukhori, Juz I, Riyadh, Saudi Arabia: Dar Thaibah Riyadh Saudi Arabia, 2005/1426, h. 391.

116 Mumtäz Vol. 1 No. 2, Tahun 2017 
Prilleltensky, Isaac \& Dennis Fox, Psikologi Kritis: Metaanalisis Psikologi Modern, Jakarta: Teraju, 2005.

Purwanto, Ngalim, Ilmu Pendidikan: Teoritis dan Praktis, Bandung: Remdja Karya, 1985.

Royan, Frans M, The Smart Marketer in Café: Strategi memaksimalkan Penetrasi Produk, Jakarta: Gramedia Pustaka Utama, 2004.

Al-Samarqany, Abu Al-laits Nashr ibn Muhammad ibn Ahmad ibn Ibrahim, Bahrun Al 'Ulum, Beirut: Dâr Al-Kutub Al-'Alamiyah, t.th.

Sya'bi, Ahmad, Kamus Annur: Indonesia-Arab, Arab Indonesia, Surabaya: Penerbit Halim, 1997. 
118 Mumtäz Vol. 1 No. 2, Tahun 2017 